\title{
Business Process Modeling: Current Issues and Future Challenges
}

\author{
Marta Indulska ${ }^{1}$, Jan Recker ${ }^{2}$, Michael Rosemann ${ }^{2}$, and Peter Green ${ }^{1}$ \\ ${ }^{1}$ UQ Business School, The University of Queensland, St Lucia, QLD, 4072, Australia \\ \{m. indulska, p.green\} @business.uq.edu.au \\ ${ }^{2}$ Business Process Management Group, Faculty of Science and Technology, \\ Queensland University of Technology, Brisbane, QLD, 4000, Australia \\ $\{j . r e c k e r, m . r o s e m a n n\}$ aqut.edu.au
}

\begin{abstract}
Business process modeling has undoubtedly emerged as a popular and relevant practice in Information Systems. Despite being an actively researched field, anecdotal evidence and experiences suggest that the focus of the research community is not always well aligned with the needs of industry. The main aim of this paper is, accordingly, to explore the current issues and the future challenges in business process modeling, as perceived by three key stakeholder groups (academics, practitioners, and tool vendors). We present the results of a global Delphi study with these three groups of stakeholders, and discuss the findings and their implications for research and practice. Our findings suggest that the critical areas of concern are standardization of modeling approaches, identification of the value proposition of business process modeling, and model-driven process execution. These areas are also expected to persist as business process modeling roadblocks in the future.
\end{abstract}

Keywords: business process modeling, Delphi study, issues, challenges.

\section{Introduction}

Business process modeling - an approach to graphically display the way organizations conduct their business processes - has emerged as an important and relevant domain of conceptual modeling [1]. It is considered a key instrument for the analysis and design of process-aware Information Systems [2], organizational documentation and re-engineering [3], and the design of service-oriented architectures [4]. To that end, business process models typically describe in a graphical way at least the activities, events/states, and control flow logic that constitute a business process. Additionally, the models may also include information regarding the involved data, organizational and IT resources, and potentially other artifacts such as external stakeholders, goals, risks and performance metrics (e.g., [5]).

While much academic literature is dedicated to various topics related to business process modeling, indications exist that practitioners struggle with various process modeling aspects and find limited support from academic literature in guiding their efforts. Overall, there is a lack of empirical studies in business process modeling that guide future research directions [6]. In line with this observation, the main goal of the 
study reported in this paper is to identify and explore the core issues with business process modeling as they are perceived by the three main stakeholder groups, i.e. practitioners, vendors and academics. In addition to the identification of the current issues, we aim to explore the upcoming issues, i.e., the process modeling challenges that are expected to be problematic in the future. In reaching such a goal, we are able to present those items that are perceived as most critical for the further development of process modeling. Accordingly, our study is based on the following two main research questions:

R1. What are the current business process modeling issues?; and

$\mathrm{R} 2$. What are the challenges in business process modeling likely to be in 5 years time?

We choose to explore the two research questions in a Delphi study setting with three separate groups of participants, viz., academics in the business process modeling domain, business process modeling practitioners, and vendors of business process modeling tool and consultancy offerings. Our objective is to identify and prioritize the most significant issues and future challenges of business process modeling, reach consensus about these, and compare the issues and challenges across the three distinct stakeholder groups.

We proceed as follows. Sections 2 and 3 detail the research design and methodology, the selection of the three groups of participants, and the specifics of the three rounds of the Delphi study. Section 4 presents a discussion of the top issues in business process modeling. Similarly, Section 5 presents the expected business process modeling challenges. In Section 6, we discuss the results from our study and detail implications for practice and research. We conclude in Section 7 with a summary of our findings.

\section{Research Approach}

\subsection{Delphi Study Design}

The technique chosen to facilitate the collection of, and consensus on, the key issues and challenges in process modeling was the Delphi technique [7] - a multiple-round approach to data collection. Delphi studies are useful when seeking consensus among experts, particularly in situations where there is a lack of empirical evidence [8]. The anonymous nature of a Delphi study can lead to creative results [9], reduces common problems found in studies that involve large groups [8] and allows for a wider participant scope due to the reduction of geographic boundaries [10]. In the case of our study, the Delphi technique is appropriate for three main reasons:

1. It facilitates obtaining expert consensus on current issues and future challenges of process modeling (and their definitions);

2. it facilitates the involvement of a large number of expert participants, in a short period of time, across many geographical boundaries and time zones; and

3. the objective of the study aligns with the general application area of the Delphi technique, which is that of forecasting and issue identification. 
One of the main determinants of success of a Delphi study is the selection of the expert panel, i.e., the study participants [11]. Instead of utilizing a statistical, representative sample of the target population, a Delphi study requires the selection and consideration of qualified experts who have deep understanding of the domain or phenomenon of interest [10]. It also requires consideration of required levels of agreement. Moreover, careful planning of the schedule of contact with participants is also required to keep the study within a relatively short period of time so as to reduce non-response.

\subsection{Participant Selection}

To understand the perceived issues and future challenges of business process modeling, it is important to acknowledge different key stakeholders. The nature, or criticality, of any business process modeling issue may vary considerably depending upon the perspective taken by the respondent. We identify three groups of stakeholders: first, the practitioners of business process modeling, that is, the business analysts, system designers and other staff that actively use business process modeling approaches in their organizations. Second, the vendors of business process modeling tools and consulting solutions providing support to the end users. Third, the academics in the business process modeling domain, who develop next generation business process modeling artifacts and provide educational services.

Acknowledging these three groups, we designed a Delphi study that was conducted in three rounds separately for each of these stakeholder groups. The risk of being unable to obtain consensus between heterogeneous panelists [12] was further motivation to divide the study into the three related groups of stakeholders. Invitations were based on the expertise of the potential participants. For academics, we screened the program committee of the Business Process Management conference series (www.bpm-conference.org), the most reputable conference in this area. Key selection criterion was the related research track record of a PC member. For vendors, we contacted key management staff from leading tool and methodology providers, as reported in current market studies (e.g., $[13,14]$ ). For practitioners, we contacted the process managers, and similar positions, of large international corporations, who the research team knew through previous collaborations.

Regarding an appropriate panel size per expert group, typically, involvement rates of 10 participants are recommended [15] to overcome personal bias in consensus seeking. Seeking to surpass this recommendation, overall, invitations to the study were sent to 134 carefully screened experts (40 practitioners, 34 vendors, 60 academics), including 11 invitations based on referrals from invited participants. Of

Table 1. Response rates across all rounds of the Delphi study

\begin{tabular}{lllll}
\hline Panel group & $\begin{array}{l}\text { Response to } \\
\text { initial contact }\end{array}$ & $\begin{array}{l}1^{\text {st }} \text { round } \\
\text { response }\end{array}$ & $\begin{array}{l}2^{\text {nd }} \text { round } \\
\text { response }\end{array}$ & $\begin{array}{l}3^{\text {rd }} \text { round } \\
\text { response }\end{array}$ \\
\hline Academics & 28 & 26 & 26 & 25 \\
Vendors & 21 & 21 & 18 & 18 \\
Practitioners & 24 & 23 & 22 & 19 \\
Total & $\mathbf{7 3}$ & $\mathbf{7 0}$ & $\mathbf{6 6}$ & $\mathbf{6 2}$ \\
\hline
\end{tabular}


these, initially 73 experts agreed to participate, a $54.48 \%$ response rate. Table 1 shows the ongoing response rates over the three rounds of the Delphi study. By the 3rd round of the study, 62 experts were involved - an $84.93 \%$ ongoing participation rate.

\section{Study Conduct}

\subsection{Delphi Study Rounds}

Our objective in conducting the Delphi Study was three-fold: First, to identify the key issues and future challenges of business process modeling, as perceived by the different panels. Second, to establish consensus on the issues and challenges. Third, to obtain and compare the rankings of the issues and challenges based on their perceived relative importance. According to our three objectives, our study was carried out over three rounds, matching recommendations for a relatively complete Delphi study [16].

In the first round, each participant was asked to list five current issues and five future challenges in business process modeling, together with a brief description of each issue/challenge. Overall, we received 70 (participants) x 2 (issues/challenges) $\mathrm{x}$ 5 (items) $=700$ individual response items. To overcome challenges related to the number of response items, differences in terminology, term connotation and writing styles, we then codified each response item into higher level categories. For instance, we received two separate issue response items "No universal standard, and / or not knowing which standard to use, e.g. UML, BPMN, XPDL, etc." and "Lack of a standard modeling language". Both items can be coded to a higher-order issue "standardization of modeling notations, tools, and methodologies".

In ensuring reliability and validity of this coding, we performed the exercise in multiple rounds. First, three researchers independently coded each of the 700 response items into a higher level category. In a second round, two researchers independently were exposed to the three codifications from the $1^{\text {st }}$ coding round, and created individual, revised $2^{\text {nd }}$ round coding drafts. In a third round, the fourth research group member consolidated the revised codifications and resolved any classification conflicts. We believe that through this multi-round approach we ensured inter-coder reliability as well as validity of the codification exercise.

The second round of the study was designed to obtain consensus from the participants on the codified issues and challenges, as well as on the definitions of the new higher-order categories. The communication for this round provided each participant with a personalized email containing his or her original responses, the agreed classifications per response item, and descriptions of the classifications. The participants were asked to indicate their level of satisfaction with the classification of their responses and the definitions of the classifications, and to provide additional information or suggestions if they were not satisfied with the classification. We received mostly positive responses on our codification (e.g., "Your categorization is close to the mark.") as well as a small number of coding and/or definition improvement suggestions (e.g., "Tool support is misleading. I think something like tool complexity would be more appropriate.").

It has been recognized that there are times when consensus between panelists is not possible [12]. However, there is also a lack of indication in the literature as to possible 
Table 2. Satisfaction ratings for response codification

\begin{tabular}{llll}
\hline & Academics & Vendors & Practitioners \\
\hline Issues & & & \\
Average satisfaction score & 8.338 & 9.000 & 8.791 \\
Standard deviation & 1.853 & 1.185 & 1.143 \\
Challenges & & & \\
Average satisfaction score & 8.442 & 8.638 & 8.883 \\
Standard deviation & 1.520 & 1.468 & 1.150 \\
\hline
\end{tabular}

measures for determining consensus. A recent Delphi study [17] utilized a satisfaction rating of 7.5 (out of 10). In our study, we asked the participants to rate their satisfaction on a scale of 1 to 10 (10 being highest) and assumed consensus at an average satisfaction level of 8 and a standard deviation below 2.0. As shown in Table 2, average satisfaction scores ranged from 8.338 (Issues, Academics) to 9.000 (Issues, Vendors), with standard deviations ranging from 1.853 (Issues, Academics) to 1.143 (Issues, Practitioners).

While our initial study plan allowed for multiple rounds of consensus building during this second stage of the study, the results obtained indicate that our multiplecoder approach to data classification resulted in the participants achieving the required consensus levels at the first iteration of the second round, which, in turn, allowed us to stop the consensus-building process at this stage. At the end of round two, and after making required changes to categories and/or definitions, where appropriate, all response items were ranked in descending order of 'frequency of occurrence', with items such as value of business process modeling (15 times), training (13 times), standardization (11 times) and model-driven process execution (9 times) being most frequently mentioned.

We recognize that frequency of occurrence is not an accurate measure of criticality, importance or priority. Accordingly, in the third round of the Delphi study, the experts were asked to assign to the response items a weighting that reflects the respondent's relative importance of the particular item. In this round, data collection was carried out via a study website, with separate log-ins for the different expert panels. The participants were provided with the list of frequently mentioned issues and a separate list of frequently mentioned challenges (we defined 'frequently mentioned' as each item that was mentioned more than once in the first two rounds), together with their definitions. Overall, practitioners received a list of 14 issues and 13 challenges, while academics received lists of 21 and 16 items, and vendors received lists with 13 and 10 items. Each participant was given 100 points to assign across any of the issues, and 100 points to assign across any of the future challenges. The participants were free to assign the 100 points in any distribution, with the only condition being that exactly one hundred points were assigned across each of the lists. The online submission was only enabled when the participant met this condition for each of his/her two lists.

The collected data was then analyzed, and the average weightings of each issue and challenge were derived. From these calculations, we were able to derive top 10 lists, based on the average weightings, for process modeling issues and challenges for each of the three Delphi study groups. The results are listed in the Appendix. 


\subsection{Classification of Results}

To better understand the nature, and implications, of the issues and challenges, we were interested in identifying the key capability area to which an issue or challenge applies. For instance, a challenge, 'tool support', clearly pertains to the availability (or lack thereof) of appropriate IT-based solutions to support the act of modeling, while a challenge 'governance' pertains to the establishment of appropriate organizational roles, duties and responsibilities for business process modeling.

In order to identify to which capability area the issues and challenges relate, we adopted a well-established and empirically tested model of the capability areas that are required to establish, and progress, Business Process Management (BPM) in an organization (e.g., $[17,18])$. This model informs six capability areas, viz., strategic alignment, governance, method, IT, people, and culture. With business process modeling being an essential component of BPM, we adopted the capability area definitions to the more specific business process modeling context as follows (scope modifications highlighted in italic):

- Strategic Alignment is the continual tight linkage of business process modeling to organizational priorities and processes, enabling achievement of business goals.

- Governance establishes relevant and transparent accountability and decisionmaking processes to align rewards and guide actions in business process modeling.

- Methods are the approaches and techniques that support and enable consistent business process modeling actions and outcomes.

- Information Technology is the software, hardware and information management systems that enable and support business process modeling activities.

- People are the individuals and groups who continually enhance and apply their business process modeling-related expertise and knowledge.

- Culture is the collective values and beliefs that shape business process modelingrelated attitudes and behaviors.

This model allowed us to map each of the top ten issues and challenges to one of the six capability areas, and, in turn, to provide a clear representation of which aspects of process modeling are considered by the respective panel groups. Similar to the coding exercise reported above, the mapping of the top 10 lists of issues and challenges to the capability areas utilized a multi-coder approach in order to reduce bias in the classification. Three members of the research group separately classified the issues and challenges lists for each of the three study groups. The classifications were consolidated and agreement statistics were calculated. We calculated an interrater agreement using Cohen's Kappa [19] and achieved average Kappas of 0.809 for issues and 0.872 for challenges, indicating 'excellent' inter-rater agreement [20].

\section{Business Process Modeling Issues}

In a first analysis, we consider the current issues in business process modeling, as perceived by the three expert panels in our study. The Appendix lists the three top ten lists derived, and displays the rankings of the items as per their perceived relative importance. Visual inspection of these lists confirms our expectation that indeed the three stakeholder groups differ in terms of their perceived issues. Most notably, 


\begin{tabular}{|c|c|c|c|c|c|c|}
\hline & Strategic Alignment & Governance & Method & Information Technology & People & Culture \\
\hline 1 & & Standardization & & $\begin{array}{c}\text { Service Orientation } \\
\text { Model-driven Process Ex. }\end{array}$ & & \\
\hline 2 & $\begin{array}{l}\text { Value of Process Modeling } \\
\text { Value of Process Modeling }\end{array}$ & & & Model-driven Process Ex. & & \\
\hline 3 & Business-IT-Divide & & Flexibility & & & Buy-in \\
\hline 4 & Expectations Management & $\begin{array}{c}\text { Compliance } \\
\text { Standardization }\end{array}$ & & & & \\
\hline 5 & & & Methodology & & Training & iess Orien: \\
\hline 6 & & Governance & $\begin{array}{c}\text { Modeling Views } \\
\text { Modeling Level of Detail }\end{array}$ & & & \\
\hline 7 & & Standardization & $\begin{array}{c}\text { Methodology } \\
\text { Modeling Level of Detail }\end{array}$ & & & \\
\hline 8 & & & $\begin{array}{c}\text { Model Management } \\
\text { Multi-perspective Modeling } \\
\text { Model Management }\end{array}$ & & & \\
\hline 9 & & & Model Management & & Ease of Use & Adoption \\
\hline 10 & & Governance & View Integration & Model Integration & & \\
\hline
\end{tabular}

Fig. 1. Business process modeling issues, mapped to capability areas. Academic issues are highlighted dark grey, vendor issues highlighted black and practitioner issues light grey.

practitioners ranked 'Standardization' as the most significant issue (mean rating 14.316), while vendors ranked 'Model-driven process execution' (mean rating 12.222) most important, with academics perceiving 'Service orientation' (mean rating 8.440) as most important. It is further interesting to note that the number one issue for practitioners (Standardization) overall received the highest average rating of relative importance across all three lists. In contrast, the number one issue voiced by academics (Service orientation), on average, was only the tenth most important issue when considering all three lists combined. In relation to the different capability areas relevant to process modeling, Fig. 1 shows how we mapped each of the thirty issues to the capability areas as per the model by de Bruin and Rosemann [17].

Several interesting observations can be drawn. First, overall $36 \%$ of the identified top issues address methodological aspects of business process modeling. Second, five of the ten issues voiced by academics fall into this area, indicating a strong focus on the methodology of modeling. Third, the ten practitioner and vendor issues cover all six capability areas, while academics' issues do not address strategic alignment or culture. These findings suggest that vendors and practitioners are concerned with issues related to the purpose and adoption of process modeling while academics tend to concentrate on issues related to the development and evaluation of artifacts.

Regarding similarities in perceived issues across the three groups, we note that of the overall thirty top issues, the three lists contain 21 unique items, with five issues appearing in two lists (e.g., 'model-driven process execution', 'value of process modeling') and 'Standardization' and 'Model management' being the two issues that appear in each of the three top ten lists. In Table 3 we present a consolidated ordered list of perceived issues, determined by the combined average rating of each issue.

Computation of the data displayed in Table 3 allowed us to identify the most important issue in process modeling across all stakeholder groups. As can be seen, 
Table 3. Overall top 10 business process modeling issues

\begin{tabular}{|c|c|c|c|c|}
\hline Rank & Issue & Description & $\begin{array}{l}\text { Mean } \\
\text { Rating }\end{array}$ & $\begin{array}{l}\text { Std. } \\
\text { Dev. }\end{array}$ \\
\hline 1 & Standardization & $\begin{array}{l}\text { Issues related to the standardization of modeling } \\
\text { notations, tools, and methodologies. }\end{array}$ & 9.525 & 4.465 \\
\hline 2 & $\begin{array}{l}\text { Value of } \\
\text { process } \\
\text { modeling }\end{array}$ & $\begin{array}{l}\text { Issues related to the value proposition of process } \\
\text { modeling to the business. }\end{array}$ & 8.091 & 7.007 \\
\hline 3 & $\begin{array}{l}\text { Model-driven } \\
\text { process } \\
\text { execution }\end{array}$ & $\begin{array}{l}\text { Issues related to the model-driven development of } \\
\text { executable process code and the lifecycle of } \\
\text { process modeling to execution. }\end{array}$ & 6.874 & 6.252 \\
\hline 4 & $\begin{array}{l}\text { Model } \\
\text { management }\end{array}$ & $\begin{array}{l}\text { Issues related to the management of process } \\
\text { models such as publication, version, variant or } \\
\text { release management. }\end{array}$ & 5.729 & 0.666 \\
\hline 5 & $\begin{array}{l}\text { Modeling level } \\
\text { of detail }\end{array}$ & $\begin{array}{l}\text { Issues related to the definition, identification or } \\
\text { modeling of adequate levels of process abstraction. }\end{array}$ & 4.934 & 4.351 \\
\hline 6 & Methodology & Issues related to the process of process modeling. & 4.690 & 4.202 \\
\hline 7 & Governance & $\begin{array}{l}\text { Issues related to the governance of process } \\
\text { modeling efforts or projects. }\end{array}$ & 4.192 & 3.727 \\
\hline 8 & Buy-in & $\begin{array}{l}\text { Issues related to the acquisition or ongoing } \\
\text { assurance of buy-in and commitment from process } \\
\text { modeling sponsors. }\end{array}$ & 3.167 & 5.485 \\
\hline 9 & $\begin{array}{l}\text { Business-IT- } \\
\text { divide }\end{array}$ & $\begin{array}{l}\text { Issues related to the use of process modeling in IT } \\
\text { versus business scenarios, application areas or } \\
\text { communities. }\end{array}$ & 2.944 & 5.100 \\
\hline 10 & $\begin{array}{l}\text { Process } \\
\text { orientation }\end{array}$ & $\begin{array}{l}\text { Issues related to the development or education of a } \\
\text { process-aware perspective in relevant stakeholders } \\
\text { or organizational units. }\end{array}$ & 2.889 & 5.004 \\
\hline
\end{tabular}

standardization is the most significant issue in business process modeling, followed by its value, and model-driven development of executable process code. Interestingly, standardization (e.g., [21]) and model-driven process execution (e.g., [22]) are topics fervently debated in academia at present, while the value of business process modeling has attracted only little academic attention as yet.

\section{Business Process Modeling Challenges}

In a second analysis, we considered the future challenges in business process modeling, defined as issues emerging over the next five years. The Appendix lists the three top ten lists derived, and displays the rankings of the items as per their perceived relative importance. Again we note interesting results. Similar to the case of the perceived issues, the three lists contain overall 22 different challenges. However, it would appear vendors and academics perceive similar challenges. Most notably, both groups voice 'Model-driven process execution' to be the number one challenge in the future (average ratings 16.222 and 10.960), with practitioners perceiving the establishment of a business value proposition as the key future challenge (average rating 16.632). Again, the number one item of the practitioners' lists is the overall most important item as per the average rating. 


\begin{tabular}{|c|c|c|c|c|c|c|}
\hline & Strategic Alignment & Governance & Method & Information Technology & People & Culture \\
\hline 1 & Value of Process Modeling & & & $\begin{array}{l}\text { Model-driven Process Ex. } \\
\text { Model-driven Process Ex. }\end{array}$ & & \\
\hline 2 & Business-IT-Alignment & & Methodology & & & Buy-in \\
\hline 3 & Value of Process Modeling & Standardization & & Service Orientation & & \\
\hline 4 & Expectations Management & & View Integration & & Ease of Use & \\
\hline 5 & Value of Process Modeling & $\begin{array}{c}\text { Standardization } \\
\text { Governance }\end{array}$ & & & & \\
\hline 6 & & Standardization & Collaborative Modeling & & Training & \\
\hline 7 & Process Architecture & & Model Management & & Training & \\
\hline 8 & & & Data-centric Modeling & $\begin{array}{c}\text { Service Orientation } \\
\text { Model Integration }\end{array}$ & & \\
\hline 9 & & Compliance & Model Management & & & Adoption \\
\hline 10 & & & Ontology & Tool Support & & Re-use \\
\hline
\end{tabular}

Fig. 2. Business process modeling challenges, mapped to capability areas. Academic challenges are highlighted dark grey, vendor challenges highlighted black and practitioner challenges light grey.

Regarding the capability areas addressed, Fig. 2 shows the results from our mapping of the challenges to the six business process modeling capability areas.

We again identify a number of interesting observations. Most notably, the challenges of the different stakeholder groups, while overlapping to some extent, pertain to different areas of business process modeling capability. Three of the practitioners' ten challenges (buy-in, adoption and re-use) address the organizational culture, while neither academics nor vendors perceive this area to be problematic in the future. Instead, a combined seven challenges of academics and vendors address methodical aspects of business process modeling - an area apparently not expected by practitioners to be problematic. Also, while a 'people' focus is apparent in some of the challenges voiced by vendors and practitioners ('training', most notably), this capability area is not perceived as a critical challenge by academics. This group focuses its perceived challenges on the areas of method and IT, with seven of the top ten challenges falling into these two capability areas. In contrast, only one practitioner challenge (Model integration) falls in this area, with the remaining nine challenges addressing all other capability areas.

Considering a holistic view of process modeling challenges, Table 4 shows a consolidated list of the top ten future challenges across all participant groups. Similar to the case of current process modeling issues, we found that four items (Model-driven process execution, Service orientation, Model management, and Training) appeared in two of the lists, and two challenges (Value of process modeling and Standardization) were perceived as critical by all three expert panels. Interestingly, comparison of Table 3 and Table 4 shows that the overall top three issues and challenges are the same, with only the ranking as first, second or third, differing between the current state of process modeling and the future state in five years time. This finding suggests the key criticality of these current and future issues, and presents a strong call for increased attention to these aspects both in industry practice, and in process modeling research. 
Table 4. Overall top 10 business process modeling challenges

\begin{tabular}{|c|c|c|c|c|}
\hline Rank & Issue & Description & $\begin{array}{l}\text { Mean } \\
\text { Rating }\end{array}$ & $\begin{array}{l}\text { Std. } \\
\text { Dev. }\end{array}$ \\
\hline 1 & $\begin{array}{l}\text { Value of } \\
\text { process } \\
\text { modeling }\end{array}$ & $\begin{array}{l}\text { The establishment of a business value proposition } \\
\text { of process modeling. }\end{array}$ & 12.893 & 5.041 \\
\hline 2 & $\begin{array}{l}\text { Model-driven } \\
\text { process } \\
\text { execution }\end{array}$ & $\begin{array}{l}\text { The support for process enactment, automation or } \\
\text { execution based on process models. }\end{array}$ & 9.061 & 8.276 \\
\hline 3 & Standardization & $\begin{array}{l}\text { The standardization of process modeling } \\
\text { approaches, methodologies, tools, methods, } \\
\text { techniques or notations. }\end{array}$ & 8.340 & 1.221 \\
\hline 4 & $\begin{array}{l}\text { Business-IT- } \\
\text { alignment }\end{array}$ & $\begin{array}{l}\text { The use of process modeling to support alignment } \\
\text { between business and IT stakeholders, viewpoint } \\
\text { or approaches. }\end{array}$ & 5.111 & 8.853 \\
\hline 5 & $\begin{array}{l}\text { Service } \\
\text { orientation }\end{array}$ & $\begin{array}{l}\text { The support for aspects relevant to the } \\
\text { management of web services, service-oriented } \\
\text { architectures or quality of services. }\end{array}$ & 5.039 & 4.477 \\
\hline 6 & Training & The establishment of process modeling expertise. & 4.543 & 3.936 \\
\hline 7 & $\begin{array}{l}\text { Model } \\
\text { management }\end{array}$ & $\begin{array}{l}\text { The management of process model variants, } \\
\text { versions, releases, changes etc. }\end{array}$ & 4.264 & 3.736 \\
\hline 8 & Buy-in & $\begin{array}{l}\text { The acquisition or ongoing assurance of buy-in } \\
\text { and commitment from process modeling } \\
\text { sponsors. }\end{array}$ & 4.114 & 7.126 \\
\hline 9 & Ease of use & $\begin{array}{l}\text { The complexity or easiness of process modeling } \\
\text { methodologies, tools or notations. }\end{array}$ & 3.648 & 6.319 \\
\hline 10 & $\begin{array}{l}\text { Collaborative } \\
\text { modeling }\end{array}$ & $\begin{array}{l}\text { The involvement of multiple people in the } \\
\text { modeling of processes. }\end{array}$ & 3.000 & 5.196 \\
\hline
\end{tabular}

\section{Discussion and Implications}

\subsection{Discussion}

Through the analysis presented above, we identify zones of concordance and disconcordance between key stakeholder groups in business process modeling. Our findings suggest that the endeavors of academics and vendors are not always aligned to current or future needs of industry.

Notably, our study identified that the top three issues in business process modeling at the moment, considering rankings from all three participant groups, are those of standardization of process modeling, identification of the value of process modeling, and also model-driven process execution. Interestingly, the participants felt that these issues were so significant that they will still be challenges in five years to come. Our study also identified that the three groups of process modeling stakeholders have different opinions of the critical issues and challenges in the business process modeling domain. For example, while practitioners rank standardization of modeling notations to be the top critical current issue, academics perceive service-orientation as the main issue, despite the standardization issue still being largely unsolved. 
While we would agree that to a large extent the endeavors of academics and tool vendors should be visionary in nature, i.e., setting the ground work for solving challenges that practitioners are likely to face in the future, our study finds only limited indication of this situation occurring in actual industry practice. The practitioners consider their current top three issues viz. standardization, value of process modeling, and buy-in, to still be the top three challenges in five years time (albeit in a different order). This situation indicates that these issues are indeed critical and more guidance is expected on how to proceed. On the flip side, the academics consider service-orientation, model-driven process execution, and flexibility to be the current top three issues. If we consider that research takes a few years to be assimilated into industry and products, none of those issues are mentioned at all in the top ten current issues, nor future challenges, by the practitioners. The vendors have somewhat better alignment with practitioners in terms of the perceived most critical issues, with value of process modeling being the \#2 current issue. Even consideration of some of the lower ranked issues still shows lack of alignment between the current foci of the academics and vendors, as compared to the future challenges identified by practitioners. Standardization, for example, which is ranked only \#7 on the current critical issues list for academics, is the \#3 expected future challenge for practitioners.

Another interesting situation emerges when analyzing the differences within the same group of stakeholders in terms of current critical issues and future challenges. Eight of the current issues for practitioners are still expected to persist as top ten challenges in the future. The situation for academics, while considering a different set of topics, is similar, with seven current issues still expected to be in the top ten challenges in five years time.

\subsection{Implications for Practice and Research}

Our study provides implications for the industry ecosystem of end user organizations as well as vendors of tools and consultancy offerings. Through the presentation of the current issues, these stakeholder groups are informed about the key critical factors that could potentially undermine success or value generation of business process modeling projects. The identified issues also help to channel attention to the major obstacles persisting in process modeling practice (e.g., model management and standardization), and should motivate practitioners and vendors to consider appropriate solutions or at least workarounds to some of the issues. Most notably, the standardization of process modeling appears to be top on the agenda for process modeling stakeholders. For end users, this finding implies setting up, and using, an appropriately standardized modeling environment and available standards (e.g., BPMN, BPEL etc.), while for vendors it implies importance to adapt their offerings so as to incorporate existing standards.

In addition to the insights we provide to the practice of business process modeling, our work also informs a research agenda for process modeling-related research. On the basic assumption that research should consider relevant topics of future interest to practitioners, the contrast between future challenges identified by business process modeling practitioners and the current issues of interest to academics identifies a number of areas that are of interest to practitioners but do not appear as yet on the radar screen of BPM scholars. Such areas include, for instance: 
- Value of business process modeling: Research that studies the value proposition, the net benefits or the cost drivers associated with business process modeling.

- Expectations management: Research that examines the expectations and preconceptions, and the (dis-) confirmation of those, of different stakeholder groups involved in business process modeling.

- Training: Research that studies different approaches to building business process modeling expertise, the effects of expertise on the quality of business process modeling, or the key factors determining process modeling expertise.

- Process architecture: Research that examines the development, use, composition, or value of architectural models to guide the act of business process modeling.

- Adoption: Research that studies the key determinants and impediments associated with the adoption and continued use of business process modeling on an individual or organizational level.

We note that some of these areas of concern to practitioners appear to be similar in nature to a range of the established streams of research in Information Systems in general. For example, adoption [23], expectation [24] or value [25] of Information Technology are well-established domains of IS research. However, it would appear that these areas have, to date, been under-researched in the domain of business process modeling and management. This situation brings forward a challenge as well as an opportunity. Future research in these areas could build upon the body of knowledge existent in the IS domain, and extend or amend existing theories to fit the specific context of business process modeling. Some examples of how such work could be carried out already exist (e.g., [26]).

\section{Conclusions}

Business process modeling is a foundational requirement in many management and IS projects, yet it still represents a significant challenge to many organizations. This paper presents the results of the first global large-scale Delphi study on the current issues and future challenges in the business process modeling domain. The identification of the most critical issues and challenges - from three separate perspectives of academics, practitioners and vendors - enables us to develop deeper insights into the interplay of research and practice, and to propose a set of industryrelevant topics for the research community. Indeed, on the basis of our findings, we would argue that increasing the synergy between the three groups will lead to: (a) industry-relevant research that facilitates increased business process modeling maturity in organizations, in turn generating the need for research in novel modeling approaches, and, (b) the development of tools and supporting methodologies that are better suited to the needs of the market.

We identify the Delphi study approach as a potential limitation in our work. Delphi studies are said to be susceptible to a number of weaknesses including (1) the flexible nature of study design [9], (2) the discussion course being determined by the researchers [7], and (3) accuracy and validity of outcomes [27]. In our study, measures were taken to minimize their potential impact. Such measures included: (1) establishing assessment criteria for measuring inter-rater agreements; (2) use of a 
multiple coders; (3) using multiple coding rounds and (4) following established methodological guidelines for the conduct of Delphi studies (e.g., $[10,11,16])$.

In our future work we seek to provide a detailed analysis of additional qualitative responses gathered in a later fourth round of the study, which exposed the top 10 lists to all participant groups and elicited the comments of the participants. In a related stream of research, we will complement this Delphi study with a similar study on the perceived benefits of business process modeling, to provide a balanced perspective.

\section{References}

1. Davies, I., Green, P., Rosemann, M., Indulska, M., Gallo, S.: How do Practitioners Use Conceptual Modeling in Practice? Data \& Knowledge Engineering 58, 358-380 (2006)

2. Dumas, M., van der Aalst, W.M.P., ter Hofstede, A.H.M. (eds.): Process Aware Information Systems: Bridging People and Software Through Process Technology. John Wiley \& Sons, Hoboken, New Jersey (2005)

3. Davenport, T.H., Short, J.E.: The New Industrial Engineering: Information Technology and Business Process Redesign. Sloan Management Review 31, 11-27 (1990)

4. Erl, T.: Service-oriented Architecture: Concepts, Technology, and Design. Prentice Hall, Upple Saddle River (2005)

5. Scheer, A.-W.: ARIS - Business Process Modeling, 3rd edn. Springer, Berlin (2000)

6. Eikebrokk, T.R., Iden, J., Olsen, D.H., Opdahl, A.L.: Exploring Process-Modelling Practice: Towards a Conceptual Model. In: Proceedings of the 41st Annual Hawaii International Conference on System Sciences, vol. 376. IEEE, Waikoloa (2008)

7. Dalkey, N., Helmer, O.: An Experimental Application of the Delphi Method to the Use of Experts. Management Science 9, 458-467 (1963)

8. Murphy, M.K., Black, N.A., Lamping, D.L., McKee, C.M., Sanderson, C.F.B., Askham, J., Marteau, T.: Consensus Development Methods, and their Use in Clinical Guideline Development. Health Technology Assessment 2, 1-88 (1998)

9. van de Ven, A.H., Delbecq, A.L.: The Effectiveness of Nominal, Delphi, and Interacting Group Decision Making Processes. Academy of Management Journal 17, 605-621 (1974)

10. Okoli, C., Pawlowski, S.D.: The Delphi Method as a Research Tool: an Example, Design Considerations and Applications. Information \& Management 42, 15-29 (2004)

11. Powell, C.: The Delphi Technique: Myths and Realities. Journal of Advanced Nursing 41, 376-382 (2003)

12. Richards, J.I., Curran, C.M.: Oracles on "Advertising": Searching for a Definition. Journal of Advertising 31, 63-76 (2002)

13. Hall, C., Harmon, P.: The 2007 Enterprise Architecture. Process Modeling, and Simulation Tools Report. BPTrends.com (2007)

14. Blechar, M.J.: Magic Quadrant for Business Process Analysis Tools. Gartner Research Note G00148777. Gartner, Inc., Stamford, Connecticut (2007)

15. Cochran, S.W.: The Delphi Method: Formulation and Refining Group Judgments. Journal of Human Sciences 2, 111-117 (1983)

16. Linstone, H.A., Turoff, M. (eds.): The Delphi Method: Techniques and Applications [Online Reproduction from 1975]. Addison-Wesley, London (2002)

17. de Bruin, T., Rosemann, M.: Using the Delphi Technique to Identify BPM Capability Areas. In: Toleman, M., Cater-Steel, A., Roberts, D. (eds.) Proceedings of the 18th Australasian Conference on Information Systems, The University of Southern Queensland, Toowoomba, Australia, pp. 643-653 (2007) 
18. de Bruin, T.: Insights into the Evolution of BPM in Organisations. In: Toleman, M., CaterSteel, A., Roberts, D. (eds.) Proceedings of the 18th Australasian Conference on Information Systems, The University of Southern Queensland, Toowoomba, Australia, pp. 632-642 (2007)

19. Cohen, J.: A Coefficient of Agreement for Nominal Scales. Educational and Psychological Measurement 20, 37-46 (1960)

20. Landis, J.R., Koch, G.G.: The Measurement of Observer Agreement for Categorical Data. Biometrics 33, 159-174 (1977)

21. Recker, J.: Opportunities and Constraints: The Current Struggle with BPMN. Business Process Management Journal 15 (in press, 2009)

22. Ouyang, C., van der Aalst, W.M.P., Dumas, M., ter Hofstede, A.H.M., Mendling, J.: From Business Process Models to Process-Oriented Software Systems. ACM Transactions on Software Engineering Methodology 19 (in press, 2009)

23. Venkatesh, V., Davis, F.D., Morris, M.G.: Dead Or Alive? The Development, Trajectory And Future Of Technology Adoption Research. Journal of the Association for Information Systems 8, 267-286 (2007)

24. Bhattacherjee, A.: Understanding Information Systems Continuance: An ExpectationConfirmation Model. MIS Quarterly 25, 351-370 (2001)

25. Mukhopadhyay, T., Kekre, S., Kalathur, S.: Business Value of Information Technology: A Study of Electronic Data Interchange. MIS Quarterly 19, 137-156 (1995)

26. Recker, J.: Understanding Process Modelling Grammar Continuance: A Study of the Consequences of Representational Capabilities. Faculty of Information Technology, Queensland University of Technology, Brisbane (2008)

27. Ono, R., Wedemeyer, D.J.: Assessing the Validity of the Delphi Technique. Futures 26, 289-304 (1994)

\section{Appendix}

\begin{tabular}{|c|c|c|c|c|c|c|}
\hline \multirow[t]{2}{*}{ Rank } & \multirow{2}{*}{$\begin{array}{l}\text { Practitioners } \\
\text { Issue }\end{array}$} & \multirow[b]{2}{*}{$\begin{array}{l}\text { Mean } \\
\text { Rating }\end{array}$} & \multicolumn{2}{|l|}{ Vendors } & \multicolumn{2}{|l|}{ Academics } \\
\hline & & & Issue & $\begin{array}{l}\text { Mean } \\
\text { Rating }\end{array}$ & Issue & $\begin{array}{l}\text { Mean } \\
\text { Rating }\end{array}$ \\
\hline 1 & Standardization & 14.316 & Model-driven process execution & 12.222 & Service orientation & 8.440 \\
\hline 3 & Buy-in & 9.500 & Business-IT-divide & 8.833 & Flexibility & 7.480 \\
\hline 4 & Expectation management & 8.474 & Standardization & 8.778 & Compliance & 6.880 \\
\hline 5 & Training & 8.316 & Process orientation & 8.667 & Methodology & 5.960 \\
\hline 8 & Model management & 6.368 & Multi-perspective modeling & 7.333 & Model management & 5.040 \\
\hline 9 & Adoption & 6.263 & Model management & 5.778 & Ease of use & 4.920 \\
\hline 10 & Model integration & 5.632 & Governance & 5.444 & View integration & 4.640 \\
\hline Rank & Practitioners & & Vendors & & Academics & \\
\hline 3 & Standardization & 8.632 & Value of process modeling & 14.889 & Service orientation & 8.560 \\
\hline 4 & Expectations management & 7.842 & Ease of use & 10.944 & View integration & 8.560 \\
\hline 5 & Governance & 7.079 & Standardization & 9.389 & Value of process modeling & 7.160 \\
\hline 6 & Training & 6.684 & Collaborative modeling & 9.000 & Standardization & 7.000 \\
\hline 7 & Process architecture & 6.316 & Training & 6.944 & Model management & 6.960 \\
\hline 8 & Model integration & 6.289 & Service orientation & 6.556 & Data-centric process modeling & 6.560 \\
\hline 9 & Adoption & 6.132 & Model management & 5.833 & Compliance & 6.160 \\
\hline 10 & Re-use & 5.868 & Ontology & 4.889 & Tool support & 6.080 \\
\hline
\end{tabular}

